\title{
Mothers' and health workers' perceptions of participation in a child-friendly health initiative in rural South Africa
}

\author{
Ntombizodumo Mkwanazi ${ }^{1,2}$, Tamsen Rochat ${ }^{1,3}$, Bronwyne Coetzee ${ }^{3}$, Ruth Bland ${ }^{1,2,4}$ \\ ${ }^{1}$ Africa Centre for Health and Population Studies, University of KwaZulu-Natal, Somkhele, South Africa; \\ nmkwanazi@africacentre.ac.za \\ ${ }^{2}$ School of Public Health, University of Witwatersrand, Johannesburg, South Africa \\ ${ }^{3}$ Department of Psychology, Stellenbosch University, Stellenbosch, South Africa \\ ${ }^{4}$ Royal Hospital for Sick Children, University of Glasgow, Glasgow, UK \\ Received 30 October 2013; revised 28 November 2013; accepted 12 December 2013 \\ Copyright (C) 2013 Ntombizodumo Mkwanazi et al. This is an open access article distributed under the Creative Commons Attribu- \\ tion License, which permits unrestricted use, distribution, and reproduction in any medium, provided the original work is properly \\ cited.
}

\section{ABSTRACT}

Background: Primary health care clinics promote health in addition to treating illness, but are often perceived as unfriendly and frightening places for children. This research aimed to improve child-friendliness in primary health care settings in a rural, high HIV prevalence area in South Africa. Methods: As part of a larger intervention ("Amagugu" Intervention) health staff in nine primary health care clinics were trained in a child-friendliness approach. 281 enrolled mothers were invited to attend clinic with their primary school-aged children and assessed childfriendliness via structured questionnaires administered by independent assessors; a sub-group also participated in in-depth interviews. Post intervention, focus groups were conducted with 87 primary health staff to determine their experiences of providing child-friendly services. Results: Mothers rated $65 \%$ of clerks and $70 \%$ of nurses as "very friendly". Qualitative data showed that heavy clinical loads, limited human resources and inadequate infrastructure were perceived as barriers to child-friendliness, while good clinic leadership and appropriate resources facilitated child-friendliness. Post intervention most health workers reported that child-friendly health promotion activities were rewarding. Conclusions: Providing child-friendliness training and support to primary health care facilities in low-resource settings is feasible, acceptable and yielded encouraging results.
Keywords: Primary Health Care; Child-Friendliness; Health Promotion; HIV; South Africa

\section{INTRODUCTION}

In South Africa HIV care is commonly delivered in primary health care clinics (PHCs) where health workers are instrumental in supporting good adherence to antiretroviral treatment (ART) [1]. In the family context HIV-uninfected children often play an important role in supporting their HIV-infected parents, including helping them to adhere to their medication [2-5]. Therefore, increasing children's access to health care support networks has the potential to improve health outcomes in families.

However, PHCs are often not perceived as childfriendly spaces $[6,7]$. Barriers reported to lower childfriendliness includes inappropriate physical structures and job dissatisfaction or fatigue amongst health workers $[8,9]$. Facilitators include staff training on child-friendliness and engaging children with toys and activities $[10,11]$. In resource-poor settings PHCs are often overburdened, so health promotion is a low priority [12-14]. A multi-site study in Uganda, Kosovo and Pakistan found that children, parents and health workers shared frustrations with rigid health care structures and poor systems for disseminating health information [6]. Even in resource-rich settings health workers acknowledge the challenges of promoting health amongst children in primary health care $[6,15]$.

Despite being home to most of the world's families living with HIV, literature addressing the health care support needed by HIV-affected families in South and 
southern Africa is minimal [3,12,16-18]. Most has focused on the utilization of health services by sick people $[13,14,17,19,20]$ and suggests that children are often marginalised as they find health care facilities frightening $[21,22]$ and do not understand the terminology being used $[23,24]$.

A family-centred HIV disclosure intervention, the "Amagugu intervention" [25], was developed and tested in rural South Africa to support HIV-infected mothers to disclose their HIV status to their 6 - 10-year-old, HIVuninfected, children. The intervention was tested with 281 families and found to increase maternal HIV disclosure [25]. After disclosure the mother was encouraged to engage in a health promotion activity by taking her child with her to a clinic visit. The mothers were educated on the importance of early health promotion for children and provided with health education tools for use at the clinic visit. In addition, an intervention to support childfriendliness at the nine participating health facilities was developed and implemented. This research used qualitative and quantitative methodology to explore health workers' perceptions of delivering child-friendly services and presents maternal data to support improvements in child-friendliness as a result of this intervention.

\section{METHODS}

The research setting: This study was undertaken at the Africa Centre for Health and Population Studies (www.africacentre.com) in northern KwaZulu-Natal, South Africa, in a predominantly rural area with a high HIV prevalence $[1,26]$. Health care, including HIV care, is delivered through $17 \mathrm{PHCs}$ and one district hospital with a comprehensive, decentralised, HIV Treatment and Care Programme [13,27,28].

Research design: This research used both quantitative rating data from structured questionnaires administered to mothers, and qualitative data from focus groups with health workers and in-depth interviews with a sub-group of mothers. Mixed methodology was chosen because of its value in understanding health behaviours and perceptions in under-researched issues and populations $[29,30]$.

Health care initiative: A health facility intervention was developed specifically for this research, using participatory qualitative techniques to increase its relevance and acceptability for health staff. Thereafter, the training was piloted at four of the nine implementation clinics, selected to include both rural and peri-urban settings. During piloting, dialogue and feedback were elicited from staff at participating clinics to finalise the training programme and clinic resources for a child-friendliness component (see Box 1). The training was then implemented at the five remaining PHCs. The health worker training targeted a diversity of staff including nurses, HIV counsellors and clerks to maximise opportunities for
Box 1. Health care educational materials provided as part of the Amagugu intervention.

Materials provided for the children as part of the "Amagugu" intervention

The Amagugu Name Tag: Each child was provided with a name tag to assist the child to have a sense of identity and pride, and serve as a visual reminder to health staff of their commitment to ensuring that children were welcomed in the clinic.

The Clinic Checklist: The clinic checklist was designed as an "I spy" activity, to encourage the child to explore the clinic. It is a "learn by doing" tool which helped the child become familiar with the clinic processes (including patient registration and medical procedures); the infrastructure (including the waiting area and toilet); and to meet and engage with health care providers (including the clerk, other patients and the HIV nurse).

The Uthando Doll: The larger intervention included a play-forcommunication component where children were provided with ethnically-appropriate dolls. Children were encouraged to take their doll to the clinic and participate in "pretend play" of medical procedures such as checking temperatures and giving injections. Including the doll in the clinic activities encouraged the child to learn about medical procedures in a fun and non-threatening way. Clinic Visit Reminder Card: This A5 illustrated card was a reminder tool for mothers, to help them organise, plan and execute the health care visit. The card also served as an advocacy tool in the clinic where the mother could use it as a reminder for busy health staff of the commitments to provide a child-friendly clinic visit.

Materials provided for the clinic facilities

Health promotion posters: An A3 poster was designed, titled "Let's Make Clinics Child-friendly!”. The poster provided key health promotion messages and reminders about child-friendliness, including: children should be welcome at clinics even when they are not ill, health care environments are spaces for information and advice, a health care support network is important for children whose parents have chronic illnesses, play is important for children to reduce anxieties and allow health promotion learning.

A Medical Play Kit: A commercially sourced medical play kit and an Uthando doll were provided to each HIV nurse to engage the child in health demonstrations. The play kit included a stethoscope, thermometer, syringe and otoscope.

Amagugu intervention materials: As part of the intervention mothers were provided with an HIV Body Map with stickers, and health promotion playing cards. These tools were also available in the nurses' examination room during the child's visit, so that the nurses could reinforce the messages mothers had taught their children during disclosure.

improving the quality of interactions with children during clinic visits.

Data collection tools: Three data collection tools were utilized in this research: 1) Interviews with mothers $(\mathrm{N}=$ 281): These structured interviews followed the health promotion clinic visit and collected maternal ratings of child-friendliness; 2) In-depth interviews with a sub-set of mothers $(\mathrm{N}=20)$ : A group of mothers were interviewed at their homes two weeks after the Amagugu intervention, to explore their experiences of participating; 3) Health care worker focus groups $(\mathrm{N}=87)$ : Focus groups were conducted with health staff at all nine participating clinics, three months after the intervention. Focus group methodology was used to explore perceptions, opinions and attitudes towards child-friendliness. 
Prior to the research we identified five key issues from the literature [10-12,19-21,31-33] which were important for the development and uptake of this kind of intervention: 1) willingness to engage in child-friendliness; 2) activities to support child-friendliness; 3) barriers and 4) facilitators of child-friendliness; and 5) contributors to sustainability. These formed the basis of the focus group guide and were also used as guiding categories in focus group analyses.

Data analysis: Quantitative data analysis: Mothers' data from the post clinic interviews were entered into an Access database and imported into STATA 11 for analysis. Descriptive statistics were used to quantify and describe the demographic characteristics of the participants including mothers and health workers. Qualitative data analysis: Focus groups and in-depth interviews were transcribed verbatim, translated from IsiZulu to English, imported into ATLAS. ti version 7 for analysis $[34,35]$, and organised using the themes explored in the focus group and interview guides. Categories were reviewed for redundancy and similar codes and categories grouped under a single higher order category. Higher order categories which resulted from collapsing codes with similar ideas together reflected the important thematic areas linked to the focus group and interview guide categories.

Ethics permissions: Approval was granted by the University of KwaZulu-Natal Biomedical Research Ethics and the University of Witwatersrand Human Research Ethics Committees.

\section{RESULTS}

Sample: All 281 HIV-positive mothers enrolled in Amagugu completed the health promotion training; their socio-demographic and health characteristics are shown in Table 1.

Maternal intervention impact: Mothers' experiences of the clinic visit, including ratings of child-friendliness of health workers are shown in Table 2. Almost all the mothers took their child to the clinic, with a third reporting waiting less than 5 minutes to see the nurse. Approximately two-thirds of the mothers rated the clerks and nurses as "very friendly", and most reported that the nurses had used the medical play kits and the childfriendliness posters, although only a third used the HIV Body Map.

Characteristics of health workers participating in focus groups $N=87$ : Forty-one (47\%) participants were nurses, 23 (26.5\%) HIV counsellors and 23 (26.5\%) clinic clerks. The median age of participants was 39 years (IQR 31 - 49); six were male. Sixty two (71\%) participants were from rural, 17 (20\%) from peri-urban and $8(9 \%)$ from urban clinics.

Themes from the focus groups of health workers and in-depth interviews of mothers:
Table 1. Maternal and child characteristics.

\begin{tabular}{|c|c|c|}
\hline Maternal characteristics & & \\
\hline \multicolumn{3}{|l|}{ Age (years) } \\
\hline Median & 35 & \\
\hline \multirow[t]{2}{*}{ Range } & $23-54$ & \\
\hline & $\mathbf{N}$ & $\%$ \\
\hline \multicolumn{3}{|l|}{ Education } \\
\hline No education & 17 & 6.0 \\
\hline Completed some or all primary & 108 & 38.4 \\
\hline Completed some or all secondary & 148 & 52.7 \\
\hline Post school education & 5 & 1.8 \\
\hline Missing & 3 & 1.1 \\
\hline \multicolumn{3}{|l|}{ Employment } \\
\hline Employed & 90 & 32.0 \\
\hline Unemployed & 188 & 66.9 \\
\hline Missing & 3 & 1.1 \\
\hline \multicolumn{3}{|l|}{ Regular income } \\
\hline Receives regular income & 73 & 26.0 \\
\hline Does not receive regular income & 208 & 74.0 \\
\hline \multicolumn{3}{|l|}{ Hospitalisation (<12 months) } \\
\hline Yes & 30 & 10.6 \\
\hline No & 250 & 89.0 \\
\hline Missing & 1 & 0.4 \\
\hline \multicolumn{3}{|l|}{ CD4 count (most recent) } \\
\hline$\geq 501$ & 77 & 27.4 \\
\hline $351-500$ & 53 & 18.9 \\
\hline$\leq 350$ & 71 & 25.3 \\
\hline Missing & 80 & 28.5 \\
\hline \multicolumn{3}{|l|}{ HIV treatment status } \\
\hline On ART (1) & 118 & 42.0 \\
\hline Not on ART (2) & 155 & 55.2 \\
\hline Missing & 8 & 2.8 \\
\hline \multicolumn{3}{|l|}{ Child characteristics } \\
\hline \multicolumn{3}{|l|}{ Age (years) } \\
\hline Median & 7 & 7 \\
\hline \multirow[t]{2}{*}{ Range } & $5-10$ & $5-10$ \\
\hline & $\mathbf{N}$ & $\%$ \\
\hline \multicolumn{3}{|l|}{ Gender } \\
\hline Female & 140 & 49.8 \\
\hline Male & 141 & 50.2 \\
\hline \multicolumn{3}{|l|}{ Hospitalization (since birth) } \\
\hline Yes & 43 & 15.3 \\
\hline No & 221 & 78.6 \\
\hline Missing & 17 & 6.0 \\
\hline
\end{tabular}


Table 2. Maternal experiences of child-friendliness at the health promotion clinic visit.

\begin{tabular}{|c|c|}
\hline Mother reported data from clinic visit & $\mathbf{N}=\mathbf{2 8 1}$ \\
\hline \multicolumn{2}{|l|}{ Did you take your child for a clinic visit? } \\
\hline Yes & $277(98.58 \%)$ \\
\hline No & $4(1.42 \%)$ \\
\hline \multicolumn{2}{|l|}{ Did your child wear his/her name tag? } \\
\hline Yes & $276(98.22 \%)$ \\
\hline No & $5(1.78 \%)$ \\
\hline \multicolumn{2}{|l|}{$\begin{array}{l}\text { Did your child meet the clerk } \\
\text { and complete the register? }\end{array}$} \\
\hline Yes & $263(93.59 \%)$ \\
\hline No & $17(6.05 \%)$ \\
\hline Missing & $1(0.36 \%)$ \\
\hline \multicolumn{2}{|l|}{$\begin{array}{c}\text { How would you rate child-friendliness } \\
\text { of the clerk that you met? }\end{array}$} \\
\hline Very friendly & $184(65.48 \%)$ \\
\hline Neutral & $73(25.98 \%)$ \\
\hline Unfriendly & $5(1.78 \%)$ \\
\hline Don’t know (did not meet one) & $18(6.41 \%)$ \\
\hline Missing & $1(0.36 \%)$ \\
\hline \multicolumn{2}{|l|}{ Did your child complete his/her clinic checklist? } \\
\hline Yes & $271(96.44 \%)$ \\
\hline No & $8(2.85 \%)$ \\
\hline Missing & $2(0.71 \%)$ \\
\hline \multicolumn{2}{|l|}{$\begin{array}{c}\text { Did you see the Amagugu child-friendliness } \\
\text { poster at the clinic? }\end{array}$} \\
\hline Yes & $259(92.17 \%)$ \\
\hline No & $21(7.47 \%)$ \\
\hline Missing & $1(0.36 \%)$ \\
\hline \multicolumn{2}{|l|}{$\begin{array}{l}\text { How long did you wait to see the nurse } \\
\text { for the health care visit? }\end{array}$} \\
\hline$<5 \min$ & $90(32.03 \%)$ \\
\hline $5-20 \min$ & $82(29.18 \%)$ \\
\hline $20-60 \mathrm{~min}$ & $79(28.11)$ \\
\hline$>60 \min$ & $25(8.90 \%)$ \\
\hline Missing & $5(1.78 \%)$ \\
\hline \multicolumn{2}{|l|}{ How would you rate friendliness of the nurse? } \\
\hline Very friendly & $196(69.75 \%)$ \\
\hline Neutral & $62(22.06 \%)$ \\
\hline Unfriendly & $3(1.07 \%)$ \\
\hline Don't know (did not see the nurse) & $18(6.41 \%)$ \\
\hline
\end{tabular}

Continued

\begin{tabular}{cc}
\hline Missing & $2(0.71 \%)$ \\
Did the nurse use any of the following \\
Amagugu educational tools? \\
HIV Body map education tool \\
Medical play kit & $112(39.86 \%)$ \\
Child-friendliness posters & $197(70.11 \%)$ \\
\end{tabular}

1) Willingness to participate in, and acceptability of, child-friendly initiatives and health promotion for children

The importance of children's rights to friendly and accessible health facilities, emphasised in the training, resonated with most participants. In focus groups, discussion centred on beliefs about what a child-friendly clinic should or should not be. Participants felt that clinics should represent safe and welcoming places where children were not discriminated against. One 47-yearold female nurse stated: "I think it (child-friendliness) means that if the child is below the age that they can go to the clinic by themselves, they should not be scared of going to the clinic when left alone at home and they have a running stomach. They should just have that confidence that I'm used to going to the clinic and I know that they are going to help me. They can just go because they know that children are welcome at the clinic, they don't get scolded and they are not in that frightened state."

Mothers agreed that the health promotion visit encouraged their children to visit the PHCs. A 49-year-old mother of an 8-year-old boy said: "From there (after disclosing) I started talking to him about positive living, and we continued educating each other about sickness and pills and I made him have an interest in going to the clinic and enjoy it. He used to be that person that fears going to the clinic; he feared that they will give him an injection. He ended up liking the clinic and being interested in going there and wants us to go there all the time."

A 36-year-old mother of an 8-year-old girl echoed the same sentiments: "Through participating in the Amagugu intervention I got encouraged to go to the clinic because we sometimes forget. The child also enjoyed visiting the clinic".

\section{2) Activities that support child-friendly initiatives}

Table 3 summarises the activities thought to support child-friendliness in the focus groups.

\section{3) Barriers to child-friendliness}

Busy clinical settings and inadequate human resources were cited as the most important barriers to child-friendliness. A 38-year-old male nurse stated: "Sometimes it happens that the children come to the clinic and the clinic is busy in such a way that even if you want to give 
Table 3. Activities supporting child-friendliness identified in focus groups.

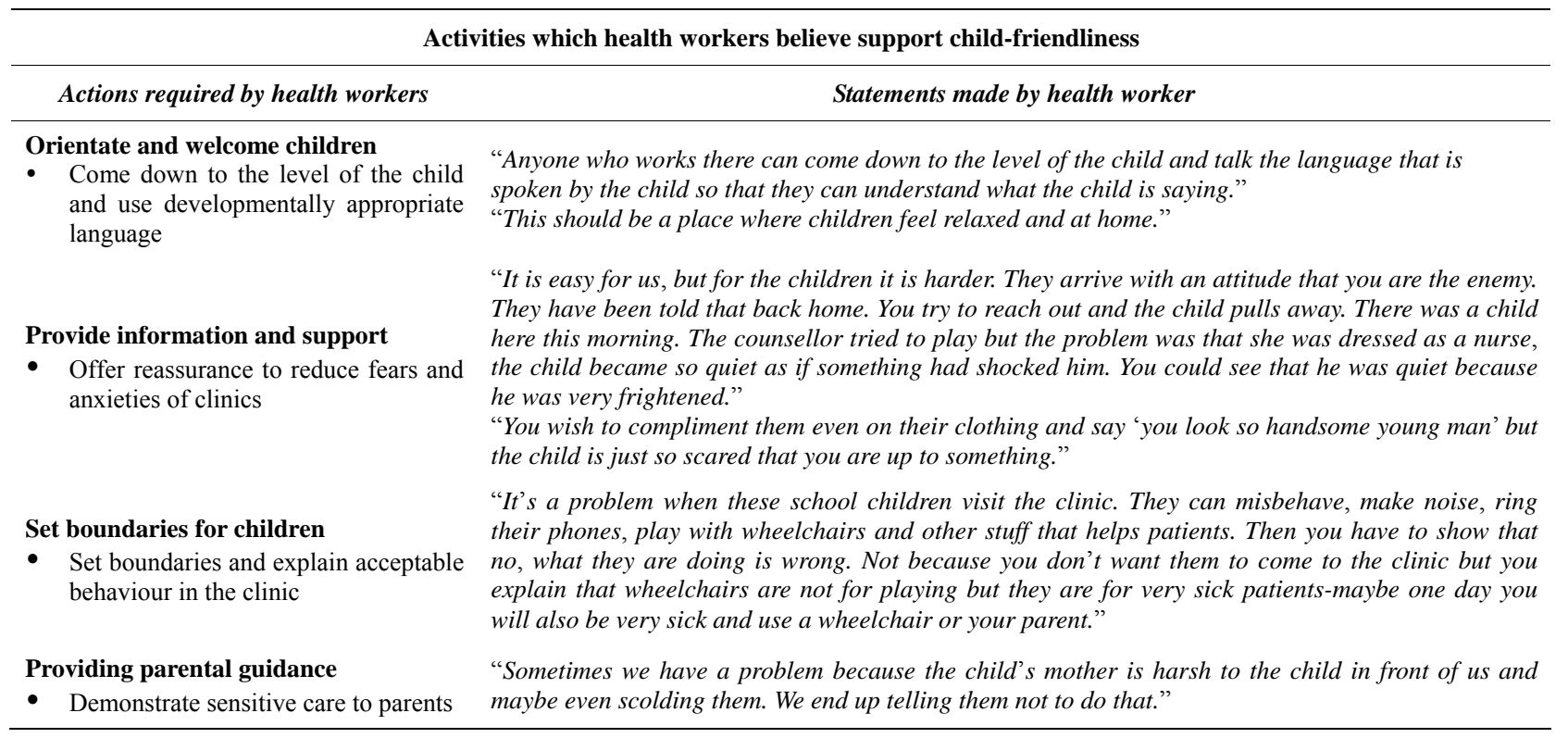

them the attention they deserve as children you end up not doing it. You cheat them because of the bad timing. Maybe you are running around, delivering babies, immunising and maybe it's only the two of you at the time and the child gets cheated of the attention they deserve."

A 42-year-old female nurse stated: "The workload is not an easy thing. Sometimes the mother comes with the child and the child does not get attention. Especially if the child is not sick, you only attend to the mother because you are pushing work and you don't even have time to be playful with the child. It's not easy in a busy clinic. You only attend to the illness and do what you are doing."

Some health workers supported the child-friendliness intervention but complained about the mothers and did not appear to appreciate the "service role" of the clinics that remain open until 16:30 hours. A 43-year-old female nurse complained about the mothers: "Maybe you can rectify with them (mothers) that they cannot come whenever because some mothers arrive at $4 \mathrm{pm}$ and you have already locked the room and they say [Imitating the mother] "This is the only time I could come, I was told to come whenever"... then it will be like we have an attitude towards them whereas we know we have to attend to them."

A point of discord that featured strongly in the focus groups related to the gap between being willing to practise child-friendliness and not having the tools or human resources to do this. A 36-year-old female counsellor stated: "Yes, we try our best (to be child-friendly) but there are no toys or fun things that the staff can use. We do not have enough time for it because this is a busy clinic and we have many patients with different sick- nesses."

The lack of child-friendly spaces was frequently raised, as one 30-year-old female HIV counsellor stated: "Because there is no place where the children can play as children, so sometimes it can appear as if they are not taken good care of, but it (child-friendliness) is doable."

Participants also highlighted that health care work was emotionally draining, and at times they felt overwhelmed with critically ill patients. For example, a 40-year-old female nurse stated: "Maybe it is [hard] because children that come for health promotion are not sick. They have an image they are expecting-they expect that they will find a person that will be smiling and then they are met with not what they expected... It's not that you want to be like that but you have this load."

\section{4) Facilitators of child-friendliness}

Participants discussed ways to be child-friendly in the face of staff shortages. One idea was to share tasks among health workers. A 39-year-old female HIV counsellor's idea was: “... we can choose this Room 2 and have a counsellor that will just attend to them (children) and it could be fun whilst the mothers are consulting nurses with their many files. The counsellor can just keep them busy."

Participants agreed that the Amagugu materials assisted them despite working in an overcrowded, rural, clinic. A 25-year-old female nurse was pleased with the intervention and stated: "We orientate children using Amagugu materials and we are able to present health information in a fun-filled way. They start there at the front desk by the clerk and we try to welcome them. Sometimes the time is against us but we try. Sometimes they just get excited and jump if they recognise Amagugu stuff'. 
For many participants, the ability to be child-friendly was connected to the leadership of the clinic, and how emotionally supportive they were to the health staff. In one clinic the sister-in-charge was regarded by the clinic staff to be "loving and caring"; participants from this clinic reported that it was easy to follow her lead. A 44year-old female general assistant made the following statement: "We are grateful for Clinic $X$ because the mother [referring to the sister-in-charge] that is managing, the supervisor, is loving. Even when she is busy she can allocate someone else to take children around. This is a friendly clinic to anyone, not just children."

5) Sustainability of child-friendly initiatives and rewards for participating health staff

Participants highlighted, and recognised, the value of providing kind and sensitive care to children for their own sense of wellbeing and pride in their work. This made child-friendliness easier to maintain and sustain. This was most commonly expressed in participants' enjoyment of children's expressed aspirations to become health care providers themselves. A 42-year-old female nurse gave the following example: "We greet them (children), we welcome them very nicely and ask them who they are, and introduce ourselves and even ask them 'what would you like to study to be (when you grow up)'? Some even say, 'I would like to study to be a nurse'. Maybe it is because we have talked to them nicely".

A 55-year-old nurse stated: "I was happy to see them (the Amagugu children) because of their cleverness. Even the way they do things. You can see that if these children can continue with this thing they have started, they can be able to help even the person they meet on the street. ... You enjoy being with them even if it is for a short period. If we can have enough time it would be wonderful".

Participants felt that the activities in the intervention package encouraged a positive interaction between them and the children. A 42-year-old female nurse explained how they participated in the intervention: "They have these name tags and use the playing cards that you gave us and the doll. They end up seeing themselves as health workers. For instance if you give them a stethoscope and let them use it. They see themselves as doctors or see themselves as nurses".

A 40-year-old female nurse was impressed by some of the Amagugu children that came for the health promotion visit: "What I can say is there are those that are quiet and those that are open..... we had twins, one twin was quiet and the other one was energetic and talking about HIV and saying what she learnt at Amagugu, showing how the HIV enters the body".

A 34-year-old male nurse expressed his exciting experience of interacting with the study children: "The one (child) that I saw was clever and was asking questions, she was checking out the stethoscope and asking 'is this for seeing inside'? She even wanted to leave with the doll and was putting it in her bag. They come with different ideas and expectations. Like the one that came and said 'I am here to work'. That child ended up ordering for her mother: 'Give my mother this one, check her BP, use the thermometer'. When that Amagugu child came and said I am here to work, I got interested and thought 'that is an idea' and wanted to see and I said 'let's work'. It becomes fun".

Participants talked of the challenges of performing painful procedures on children, and the important role played by the intervention materials in making children less frightened of the clinics. A 40-year-old female nurse said: "... to know what is happening in the clinic is important-sometimes painful stuff like injections-but it is important for children to get the knowledge. For instance because there are these play kits, we can demonstrate that your child is sick, s/he must get an injection. It's important that the child knows that sometimes an injection is needed in order to get better".

A few people were not enthusiastic about the childfriendly intervention. One 40-year-old female nurse reported that even though the intervention was there, she sometimes forgot about it.... but when she remembered she tried to be friendly to children. She said: "I beg to differ. I don't have the same views because we don't have time for these children. I for instance, forget about them and find myself asking them: "Who are you by the way?" Because I'm seeing someone that is disturbing me while I'm busy and then I remember and I try to do damage control."

A 28-year-old female counsellor agreed and went on to say: I agree with [referring to Nurse] when they (children) come we are really busy, I did not even know who they were. I just heard Igugu, but I did not know what Igugu was. I did not even attend to them because here at Clinic X it's really busy. Things are turning upside down, and it's not a child's play. I don't want to lie I have not entertained them (children).

\section{DISCUSSION}

This study demonstrated that providing training and simple tools for child-friendliness and health promotion in a resource-poor, high HIV prevalence area was well accepted by health workers and mothers. This intervention was specifically aimed at the large group of HIVuninfected but exposed children, on whom there is limited literature regarding their psychosocial support [18]. However, the child-friendliness approach that was introduced has benefits for all children irrespective of their HIV status.

Encouragingly, most health workers believed that child-friendliness was a good idea, an important step in 
eliciting behaviour change [36,37]. Nevertheless, most admitted they had not considered this before the intervention, an observation supported in the literature which suggests that health professionals lack awareness of the importance and benefits of child-friendliness [15]. In our study, health workers suggested activities to support child-friendliness, not all of which included purchasing materials or tools, but also recognising that they could draw on their instinctive caring and parental instincts to improve their communication with children during their consultations. Some suggested allocating specific people to attend to the children where possible, a model frequently was adapted in resource-rich settings [6,32], but not feasible in many poorer settings. Indicators of childfriendliness in previous reports have included whether the environment was conducive for child play, whether toys and health promoting activities were provided, and whether someone had been allocated to lead play $[10,11$, 32].

Participants in the focus groups also appreciated the role of health promotion, despite the clinics being overwhelmed with sick patients. Health promotion enables people to increase control over, and improve, their health [15], and participants were surprised by the knowledge of the relatively young children in this project around HIV issues, and their enthusiasm to learn more. Children of different ages and with different illnesses may need different types of health promotional support. Increasing opportunities for child participation in clinic visits may improve the quality of health care provider relationships.

Many barriers to implementing child-friendliness were highlighted, mainly resulting from the great burden of HIV and tuberculosis at the clinics, leading to inadequate space for additional activities, and exhausted health staff $[8,9]$. These high levels of occupational stress have not only been reported in high HIV prevalence countries including South Africa [9] and Uganda [8] but also resource-rich settings including England [38]. The problem of dealing with painful procedures was also identified, with participants suggesting that children themselves can present barriers to engaging with health staff because of their innate fear of PHCs, something highlighted in previous research [10,21,22,24,39,40]. However, participants recognised the role of play in helping children understand about medical procedures.

Participants expressed their appreciation of the children's responses to child-friendly activities, using words such as "fun", "happy" and "enjoy" when describing their encounters with the children in this intervention. Often health workers in resource-poor settings are criticised for their lack of motivation and poor attitude to patients [9], but the demands on them are immense. Providing training on child-friendliness appeared to be something that health workers appreciated, responded to, and found rewarding. An important point brought up by one participant was the clinic leader being a good role model. She explained that being friendly to all children, and in fact to all patients in her clinic was something that was easy to do as the sister-in-charge provided a loving and empathetic example. Placing more emphasis on the qualities of the person in charge of PHCs has the potential to change the overall quality of services provided. Further, interactions with children which are rewarding may help to re-sensitise busy over burdened nurses in their caring role.

This was a small study in a specific geographic area. However, the findings are likely to resonate with other areas of southern Africa with similar problems. While some South African research exists to guide the use of play in health settings and the provision of psycho-social support for children [12,16,41,42], very little research has examined children's own experience of health care services. The existing evidence base is limited to a few, mostly qualitative studies in Europe, Australia and North America $[11,19,33,43]$. It would be important to explore children's experiences in future studies.

In conclusion, ensuring child-friendly services at health facilities not only helps to establish a productive and trusting health care relationship but also prepares children for periods of illness and hospitalisation $[10,33]$. Although child-friendliness and health promotion are not priorities in PHCs in resource-poor settings, introducing them has the potential to improve the experience of health visits for children and their parents and be rewarding for health workers.

\section{ACKNOWLEDGEMENTS}

This project was funded by the Canadian International Development Agency (CIDA). We are grateful to mothers and the health workers from nine clinics that participated. We thank Hlengiwe Mtolo (project administrator), Samukelisiwe Dube, Bonakele Gumede and Philani Sithole (research counsellors), Zanele Msane and Zodwa Ngubane (data capturers), Colin Newell (database management), Africa Centre Community Advisory Board and External Relations/Community Engagement Offices for their support throughout the project.

\section{REFERENCES}

[1] Bärnighausen, T., et al. (2012) HIV status and participation in HIV surveillance in the era of antiretroviral treatment: A study of linked population-based and clinical data in rural South Africa. Tropical Medicine \& International Health, 17, e103-e110. http://dx.doi.org/10.1111/j.1365-3156.2012.02928.x

[2] Edwards, L.V., et al. (2012) Am I my mother's keeper? Children as unexpected sources of social support among African American women living with HIV-AIDS. Journal of Black Studies, 43, 571-595.

http://dx.doi.org/10.1177/0021934712440171 
[3] Mkwanazi, N.B., et al. (2012) Disclosure of maternal HIV status to children: Considerations for research and practice in sub-Saharan Africa. Future Virology, 7, 11591182. http://dx.doi.org/10.2217/fvl.12.109

[4] Madiba, S. and Matlala, C. (2012) Disclosure of parental HIV positive status: What, why, when, and how parents tell their children in the era of HAART in South Africa. World Journal of AIDS, 2, 194-202. http://dx.doi.org/10.4236/wja.2012.23025

[5] Visser, M., et al. (2012) Development and piloting of a mother and child intervention to promote resilience in young children of HIV-infected mothers in South Africa. Evaluation and Program Planning, 35, 491-500. http://dx.doi.org/10.1016/j.evalprogplan.2012.04.001

[6] Clarke, A. and Nicholson, M.S. (2007) The child friendly healthcare initiative-An update. Paediatric Nursing, 19, 36-37. http://dx.doi.org/10.7748/paed2007.10.19.8.36.c4465

[7] Emeghebo, L. (2012) The image of nursing as perceived by nurses. Nurse Education Today, 32, e49-e53. http://dx.doi.org/10.1016/j.nedt.2011.10.015

[8] Nabirye, R.C., et al. (2011) Occupational stress, job satisfaction and job performance among hospital nurses in Kampala, Uganda. Journal of Nursing Management, 19, 760-768. http://dx.doi.org/10.1111/j.1365-2834.2011.01240.x

[9] Jewkes, R., Abrahams, N. and Mvo, Z. (1998) Why do nurses abuse patients? Reflections from South African obstetric services. Social Science \& Medicine, 47, 17811795. http://dx.doi.org/10.1016/S0277-9536(98)00240-8

[10] Bishop, K.G. (2008) From their perspectives: Children and young people's experience of a paediatric hospital environment and its relationship to their feeling of wellbeing.

[11] Kennedy, I. (2010) Getting it right for children and young people: Overcoming cultural barriers in the NHS so as to meet their needs.

[12] Govender, L., et al. (2006) Pediatric nursing in the context of the HIV/AIDS epidemic in resource-poor settings-balancing the "Art and the Science". Holistic Nursing Practice, 20, 247-254. http://dx.doi.org/10.1097/00004650-200609000-00008

[13] Janssen, N., et al. (2010) Successful paediatric HIV treatment in rural primary care in Africa. Archives of Disease in Childhood, 95, 414-421. http://dx.doi.org/10.1136/adc.2009.169367

[14] Rujumba, J., Mbasaalaki-Mwaka, C.L. and Ndeezi, G. (2010) Challenges faced by health workers in providing counselling services to HIV-positive children in Uganda: A descriptive study. Journal of the International AIDS Society, 13, 9. http://dx.doi.org/10.1186/1758-2652-13-9

[15] Whiting, L.S. (2001) Health promotion: The views of children's nurses. Paediatric Nursing, 13, 27-31. http://dx.doi.org/10.7748/paed2001.04.13.3.27.c733

[16] Rochat, T.J. and Mitchell, C. (2011) Young children and HIV in Sub-Saharan Africa: Implications for practice and intervention, in international perspective on children and mental health.
[17] Richter, L.M., et al. (2012) Evaluation of a brief intervention to improve the nursing care of young children in a high HIV and AIDS setting. Nursing Research and Practice, 2012, 15. http://dx.doi.org/10.1155/2012/647182

[18] McNally, L.M., et al. (2006) HIV-exposed but uninfected children: Why are they vulnerable? Vulnerable Children and Youth Studies, 1, 139-148.

http://dx.doi.org/10.1080/17450120600872241

[19] Darbyshire, P. (2013) A review of palliative care and support services in south tyrol for children and young people living with a life-threatening or life-limiting illness and their families.

[20] Gibson, F., et al. (2010) Children and young people's experiences of cancer care: A qualitative research study using participatory methods. International Journal of Nursing Studies, 47, 1397-1407.

http://dx.doi.org/10.1016/j.ijnurstu.2010.03.019

[21] Kikuta, A., et al. (2011) Practices and perceptions regarding pain and pain management during routine childhood immunizations: Findings from a focus-group study with nurses working at Toronto Public Health, Ontario. Canadian Journal of Infectious Diseases \& Medical Microbiology, 22, 43-48.

[22] Norton-Westwood, D. (2012) The health-care environment through the eyes of a child-Does it soothe or provoke anxiety? International Journal of Nursing Practice, 18, 7-11. http://dx.doi.org/10.1111/j.1440-172X.2011.01995.x

[23] Cox, E.D., Smith, M.A. and Brown, R.L. (2007) Evaluating deliberation in pediatric primary care. Pediatrics, 120, e68-e77. http://dx.doi.org/10.1542/peds.2006-2602

[24] Coyne, I. (2006) Consultation with children in hospital: Children, parents' and nurses' perspectives. Journal of Clinical Nursing, 15, 61-71. http://dx.doi.org/10.1111/j.1365-2702.2005.01247.x

[25] Rochat, T., Mkwanazi, N. and Bland, R. (2013) Maternal HIV disclosure to HIV-uninfected children in rural South Africa: A pilot study of a family-based intervention. BMC Public Health, 13, 147. http://dx.doi.org/10.1186/1471-2458-13-147

[26] Tanser, F., et al. (2013) High coverage of ART associated with decline in risk of HIV acquisition in rural KwaZuluNatal, South Africa. Science, 339, 966-971. http://dx.doi.org/10.1126/science. 1228160

[27] Hontelez, J., et al. (2012) The impact of antiretroviral treatment on the age composition of the HIV epidemic in sub-Saharan Africa. AIDS, 26, S19-S30. http://dx.doi.org/10.1097/QAD.0b013e3283558526

[28] Houlihan, C.F., et al. (2010) Cohort profile: Hlabisa HIV treatment and care programme. International Journal of Epidemiology, 40, 318-328. http://dx.doi.org/10.1093/ije/dyp402

[29] Leech, N.L. and Onwuegbuzie, A.J. (2009) A typology of mixed methods research designs. Quality \& Quantity, 43, 265-275. http://dx.doi.org/10.1007/s11135-007-9105-3

[30] Onwuegbuzie, A.J., et al. (2009) Toward more rigor in focus group research: A new framework for collecting and analyzing focus group data. International Journal of 
Qualitative Methods, 8, 1-21.

[31] Coyne, I. and Kirwan, L. (2012) Ascertaining children's wishes and feelings about hospital life. Journal of Child Health Care, 16, 293-304.

[32] Gaskell, S., et al. (2005) Taking the sting out of needles: Education for staff in primary care. Paediatric Nursing, 17, 24-28.

http://dx.doi.org/10.7748/paed2005.05.17.4.24.c986

[33] Moore, L. and Kirk, S. (2010) A literature review of children's and young people's participation in decisions relating to health care. Journal of Clinical Nursing, 19, 2215-2225.

http://dx.doi.org/10.1111/j.1365-2702.2009.03161.x

[34] Friese, S., (2012) Qualitative data analysis with ATLAS. SAGE Publications Limited.

[35] Muhr, T. and Friese, S. (2004) User's manual for ATLAS. Scientific Software Development, Berlin.

[36] Rowe, A.K., et al. (2005) How can we achieve and maintain high-quality performance of health workers in lowresource settings? The Lancet, 366, 1026-1035. http://dx.doi.org/10.1016/S0140-6736(05)67028-6

[37] Scott, T., et al. (2003) Implementing culture change in health care: Theory and practice. International Journal for Quality in Health Care, 15, 111-118. http://dx.doi.org/10.1093/intqhe/mzg021

[38] Reed, P., et al. (2003) Promoting the dignity of the child in hospital. Nursing Ethics, 10, 67-76.

http://dx.doi.org/10.1191/0969733003ne540oa

[39] Roohafza, H., et al. (2009) Impact of nurses clothing on anxiety of hospitalised children. Journal of Clinical Nursing, 18, 1953-1959.

http://dx.doi.org/10.1111/j.1365-2702.2008.02745.x

[40] Salmela, M., Aronen, E. and Salanterä, S. (2011) The experience of hospital-related fears of 4- to 6-year-old children. Child: Care, Health and Development, 37, 719-726. http://dx.doi.org/10.1111/j.1365-2214.2010.01171.x

[41] Richter, L., Chandan, U. and Rochat, T. (2009) Improving hospital care for young children in the context of HIV/ AIDS and poverty. Journal of Child Health Care, 13, 198-211. http://dx.doi.org/10.1177/1367493509336680

[42] Richter, L.M., et al. (2012) Evaluation of a brief intervention to improve the nursing care of young children in a high HIV and AIDS setting. Nursing Research and Practice, 2012, Article ID: 647182. http://dx.doi.org/10.1155/2012/647182

[43] Parker, G., et al. (2011) Evaluating models of care closer to home for children and young people who are ill. 